\title{
EKSPRESI DUCHENNE SMILE DAN SUASANA KOTA: OBSERVASI DI BEBERAPA PUSAT KOTA YANG SEDANG TAHAP PEMBANGUNAN ULANG
}

\author{
Fadhilah Ahmad Qaniah \\ Prodi Sains Psikologi Universitas Indonesia \\ Penulis korespondensi email: qaniah13@gmail.com
}

\begin{abstract}
The atmosphere of the city created from pshysical characteristics of various urban spatial plans and social interaction in it. The perceived visual component provided sensations that directs individual to capture quality of situation emotionally which can affect their mood. When social interaction occurs, duchenne smile expressions can appear when individual feel positive emotion. However, city atmosphere can change when there is unfinished redevelopment of public facilities. This can affect the form of urban spatial and potential social interactions that can affect individual moods. This study aims to see how much duchenne smile expressions appear in downtown area in Kenadi and South Jakarta. The author chose city center of Kendari and Jakarta because they have good public facilites. The city of Kendari is currently rebuilding several of its facilities in city centers since 2019. Result show that both city areas had same number of duchenne smiles in areas of consumerism and peaceful \& quiet type. However, there are differences in the number of vibrant and historic areas, its perhaps because some of the facilities in the old town and downtown Kendari at the time of observatio were in the reconstruction stage. City atmosphere is important for the image of the city becauses it provides positive emotional experiences for people who stop by or interact socially in urban environment.

Keyword: duchenne, city atmosphere, vibrant, peaceful and quiet, consumerism, historic
\end{abstract}

\begin{abstract}
ABSTRAK
Suasana kota umumnya tercipta dari karakteristik fisik berbagai tata ruang kota dan interaksi sosial di dalamnya. Komponen visual yang dirasakan memberikan beragam sensasi yang mengarahkan individu menangkap kualitas dari situasi secara emosional yang mampu mempengaruhi mood atau suasana hati mereka. Di saat interaksi sosial terjadi, ekspresi tersenyum duchenne dapat terjadi ketika individu merasakan emosiemosi positif. Namun, suasana kota dapat berubah di saat ada pembangunan ulang fasilitas publik. Hal tersebut dapat mempengaruhi bentuk tata ruang kota dan potensi interaksi sosial yang dapat mempengaruhi suasana hati individu. Penelitian ini bertujuan untuk melihat seberapa banyak ekspresi senyum duchenne yang ada pada area kota yang ramai di pusat kota Kendari dan Jakarta Selatan. Penulis memilih pusat kota Kendari dan Jakarta Selatan karena memiliki fasilitas publik yang baik. Adapun kota Kendari saat ini membangun ulang beberapa pusat kotanya sejak tahun 2019. Hasil penelitian memperlihatkan, kedua area kota memiliki jumlah frekuensi senyuman duchenne yang sama banyaknya di area suasana jenis consumerism dan peaceful and quiet. Namun, ada perbedaan jumlah di area suasana jenis vibrant dan historic, karena beberapa fasilitas di kota tua dan pusat kota Kendari saat observasi berada di tahap pembangunan ulang. Suasana kota merupakan hal yang penting untuk image kota karena memberikan pengalaman emosi positif bagi orang yang singgah atau berinteraksi sosial di lingkungan perkotaan.
\end{abstract}

Katakunci: duchenne, suasana kota, vibrant, peaceful and quiet, consumerism, historic 
Jurnal Planologi Vol. 18 No. 1, April 2021

Available: http://jurnal.unissula.ac.id/index.php/psa

\section{Pendahuluan}

Ketika seseorang merasa nyaman dengan lingkungannya, hal tersebut dapat mendukung kesehatan, kebahagiaan, dan well-being mereka (Kytta dkk, 2016). Ada beberapa riset yang berusaha untuk melihat interaksi manusia dan respon emosionalnya terhadap lingkungan kota. Misalnya, (1) perasaan senang dan nyaman ketika menikmati keindahan alam, taman, atau lapangan hijau, (2) rasa senang dan nyaman ketika melakukan aktivitas-aktivitas sosial ataupun menikmati waktu bersama teman, (3) rasa senang, tertarik, dan nyaman, ketika mengikuti berbagai event musik dan aktivitas olahraga pada sebuah kota (Roberts dkk, 2019). Alam dan lokasi hijau di perkotaan juga seringkali dianggap mampu meningkatkan kesehatan dan well-being seseorang melalui afek positif sebagai mediator (Cameron dkk, 2020). Afek positif termasuk diantaranya perasaan gembira, semangat, senang, rileks, puas, mampu beraktivitas dengan baik, dan lainnya (Effendi, 2016).

Ada beberapa riset yang memperlihatkan bagaimana seseorang mengekspresikan dirinya ketika berinteraksi lingkungannya. Freeman dkk (2012) mengatakan bahwa taman yang ada di rumah-rumah biasanya didesain oleh pemilik supaya dapat bersosialisasi dengan orang lain misalnya dengan tetangga, keluarga, atau teman, serta agar mereka dapat merasakan suasana dekat dengan alam. Taman juga dapat mendukung berbagai praktik berkebun yang positif, sehingga mampu mendukung kesehatan masyarakat sekaligus menjaga keanekaragaman hayati. Svoray dkk (2018) dalam risetnya mengatakan bahwa tata ruang kota yang terbuka dengan alam secara signifikan berasosiasi dengan ekspresi wajah bahagia (HFE). Mereka menganalisis 60.013 foto tahun 2012-2015 dengan setting tempat terbuka dengan alam. Penelitian mereka termasuk robust karena melihat keterkaitan variabel dengan jumlah data yang begitu banyak dengan menggunakan metode big data science.

Emosi-emosi positif yang dirasakan seseorang dapat diekspresikan dengan wajah tersenyum ketika berinteraksi di lingkungan. Menurut berbagai riset sebelumnya, emosi secara universal merupakan fenomena yang dapat diekspresikan, sekaligus dapat dikenali di lingkungan oleh siapapun. Manusia tampaknya dilahirkan dengan seperangkat emosi dasar (basic emotion) yang secara biologis adalah bawaan dan dikodekan secara genetik. Emosi tersebut memungkinkan seseorang untuk menilai berbagai peristiwa dan situasi, sehingga dapat memperlihatkan berbagai faktor yang mendasarinya, meskipun emosi direspon atau diregulasi berbeda di setiap budaya (Matsumoto \& Juang, 2016).

Salah satu emosi dasar (based emotion) yang dimiliki oleh manusia adalah emosi bahagia. Ada dua tipe wajah tersenyum yang umumnya diekspesikan dari emosi bahagia 
yaitu: Duchenne smile dan non-Duchenne smile. Ekspresi senyuman duchenne, juga dikenal sebagai senyuman yang tulus, genuine, felt, atau enjoyed smile, seringkali bersifat spontan refleksi dari emosi yang dialami. Senyuman duchenne dilihat dengan aktivitas otot orbicularis oculi (pipi atas) yang membuat kerutan di sudut luar mata, ditambah dengan aktivasi otot zygomatic major yang melebarkan mulut menjadi senyuman. Sementara senyuman non-Duchenne termasuk diantaranya jenis senyuman false dan miserable umumnya tidak memiliki gerakan otot mata yang berada di bagian pipi atas. Namun, tetap memberikan gerakan otot yang memperluas mulut menjadi senyuman (Ekman dkk, 2002; Andrzejewski \& Mooney, 2016).

Duchenne smile dianggap lebih positif daripada senyuman non-Duchenne. Sebagian besar penelitian terkait berusaha melihat bagaimana senyum duchenne dipersepsikan dan apa saja manfaat dari memproduksi ekspresi tersebut dengan asumsi bahwa senyum duchenne adalah ekspresi yang spontan dan hanya bisa diproduksi ketika seseorang betulbetul bahagia (Gunnery \& Hill, 2014). Senyuman duchenne cenderung melaporkan pengalaman-pengalaman emosi positif. Beberapa diantaranya rasa senang terhadap stimulus berbentuk visual, auditori, gustatori, kisnestetik, dan rasa nyaman dan terhibur, senang dan puas, atau pengalaman seperti terbebas dari ketegangan, serta senang akan kehadiran orang lain (Ekman dkk, 2002; Andrzejewski \& Mooney, 2016).

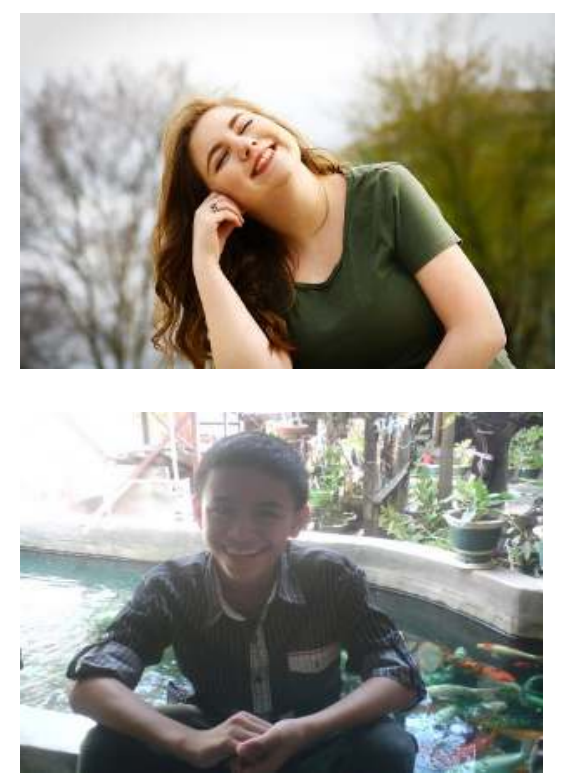

Gambar 1 dan 2. Senyum duchenne yang ditandai dengan gerakan otot di atas pipi yang membuat keriput di luar sudut mata dan ditambah gerakan otot memperlebar senyuman.

Sumber: Cooper, 2018; Penulis, 2019 
Jurnal Planologi Vol. 18 No. 1, April 2021

Berbagai pengalaman individu di perkotaan umumnya mencakup aspek suasana kota yang dirasakan secara holistik dan subjektif. Suasana kota tercipta dari berbagai karakteristik fisik tata ruang kota dan interaksi sosial di dalamnya. Gabungan komponen visual yang dirasakan seseorang dapat memberikan beragam sensasi yang mengarahkan individu untuk menangkap kualitas dari situasi secara emosional yang mampu mempengaruhi mood atau suasana hati mereka (Gandy, 2017; Stfansdottir, 2018). Suasana kota, atau urban, ataupun city atmosphere dalam riset ini merupakan hal yang dirasakan secara subjektif terhadap pengalaman holistik seseorang ketika berinteraksi di pusat kota, dan tidak hanya termasuk bentuk konkrit atmosfir bumi. Suasana-suasana kota yang ada di jalan dan fasilitas publik lainnya nampaknya memotivasi berbagai aktivitas sosial, yang mengarah kepada tingkah laku sehat dan aspek afektif yang positif. Misalnya, keberadaan jalur dan fasilitas untuk pesepeda ditemukan berasosiasi positif dengan aktivitas di luar ruangan baik bersama-sama maupun individual (Yank dkk, 2019).

Suasana kota telah dikaji dengan berbagai macam ontologi dalam disiplin ilmu yang luas. Kompleksitas dari atmosfer bukan hanya tentang skala, materi tertentu, ataupun manifestasi psikologis, namun juga salah satu konsep yang memiliki interprestasi yang berbeda-beda (Gandy, 2017). Atmosfer seringkali ditandai dengan dengan pergeseran persepsi geometri mulai dari karakteristik sensori dari pengalaman langsung hingga 'atmosfer yang telah dimanipulasi' misalnya setting ferstival musik, berbagai pusat perbelanjaan, dan lampu-lampu jalanan di keramaian (Gandy, 2017).

Ruang kota ataupun urban space dapat dimodifikasi sesuai keinginan seseorang melalui cahaya, suara, bau-bauan, atau rangsangan/stimuli-stimuli lainnya yang bisa dilihat dalam sejarah dari arsitektur dan desain kota (Gandy, 2017). Tata ruang interior bangunan seperti bioskop, teater, atau ruang konser telah diorientasikan pada produksi pengalaman sensori kolektif dengan bentuk yang lebih tinggi. Arsitek, insinyur, desainer dan lainnya telah bekerja untuk memperbaiki kualitas penyerap suara dari dinding atau efek presisi yang diciptakan oleh instalasi pencahayaan yang rumit. Sedangkan untuk ruang eksterior, atmosfer luar biasanya dibentuk untuk menimbulkan jenis pengalaman estetik tertentu untuk desain kota tua, atau jalan taman (Gandy, 2017).

Meskipun atmosfer atau suasana kota muncul karena objek lingkungan termasuk cahaya, suara, dan bau, namun suasana kota juga termasuk emosi yang dipengaruhi oleh kehidupan perkotaan (Stefansdottir, 2018). Atmosfer atau suasana kota sendiri dapat dipersepsikan sebagai kesan yang holistik (Hasse, 2014). Penerapan konsep tersebut 
diharapkan dapat memberikan wawasan baru dan lebih luas tentang pengaruh dari karakteristik tata ruang kota terhadap kehidupan perkotaan. Bagaimana suasana kota dapat mempengaruhi emosi-emosi positif yang dirasakan di lokasi yang berbeda di dalam kota. Hal tersebut mungkin dapat memberikan wawasan penting mengenai kualitas suasana kota dan kerugian mana yang perlu dikurangi untuk mengdukung transformasi yang bermakna dan berkelanjutan baik di pusat kota maupun di pinggiran kota untuk meningkatkan kelayakan hidup (Stefansdottir, 2018).

Namun, suasana kota dapat berubah di saat ada pembangunan ulang fasilitas publik. Hal tersebut dapat mempengaruhi bentuk tata ruang kota dan potensi interaksi sosial yang dapat mempengaruhi suasana hati individu. Pada tahun 2019 di kota Kendari, pemerintah kota mereka sedang membongkar beberapa fasilitas di pusat kota lama mereka, termasuk diantarnya kota tua dan perkantoran. Kota tua di Kendari dan kota baru atau berkembangnya di kec. Abeli dipisahkan oleh teluk yang cukup luas. Sejak tahun 2015, pemkot Kendari berencana membuat jembatan untuk mempercepat akses di kedua tempat. Bersamaan dengan hal tersebut, pemerintah kota juga berencana untuk menata, membangun ulang dan merevitalisasi fasilitas-fasilitas kota tua mereka misalnya taman kota, tugu kota, dan perkantoran (Noesa, 2015). Termasuk juga kantor walikota dan tugu MTQ di pusat-pusat kota tua (Rahayu, 2019; Herryl, 2019; Kurniawan, 2016; Publiksatu.co, 2019).

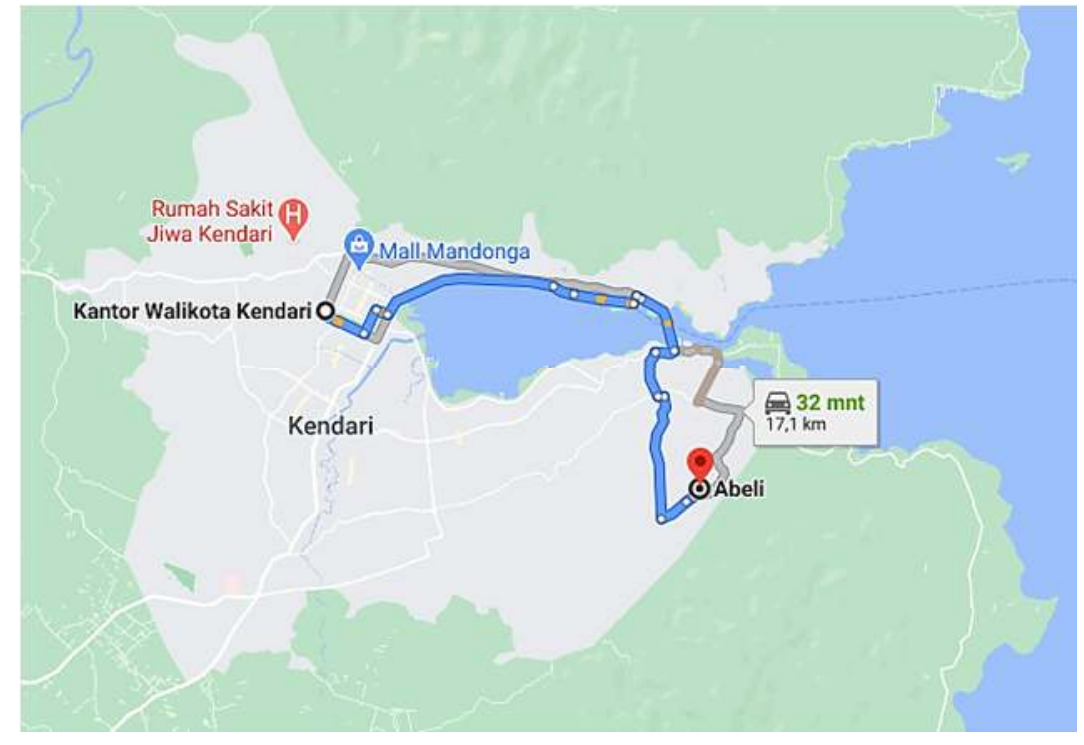

Gambar 3. Daerah kota lama Kendari di Mandonga dan pusat kota baru kendari di kec. Abeli. Sumber: googlemap.com (2020)

Stefansdottir (2018) mengemukakan bahwa ada sembilan (9) jenis suasana perkotaan. Namun, peneliti mengambil empat jenis suasana kota, karena keempat suasana tersebut 
berkarakteristik seperti pusat-pusat perkotaan dibandingkan lima jenis suasana kota lainnya. Keempat suasana kota tersebut:

Tabel 1. Empat dari sembilan Suasana Kota menurut Stefansdottir (2018)

\begin{tabular}{|c|c|c|}
\hline Jenis suasana & Gambaran area & Karakeristik suasana \\
\hline Vibrant & $\begin{array}{l}\text { Trotoar di pusat kota, kadang } \\
\text { pusat lokal dan mixed-use } \\
\text { neigborhoods (area serbaguna } \\
\text { misalnya pertokoan dan kantor } \\
\text { yang dekat dengan layanan } \\
\text { publik) } \\
\text { local centre (pusat lokal) }\end{array}$ & $\begin{array}{l}\text { streetlife, banyak pejalan kaki } \\
\text { dan individu berhenti di public } \\
\text { space, diversity } \\
\text { Mudah bertemu dengan orang, } \\
\text { semuanya fasilitas dekat dan } \\
\text { sederhana, kadangkala tidak } \\
\text { terlalu ramai }\end{array}$ \\
\hline Consumerism & Shopping mall & $\begin{array}{l}\text { Monoton, noisy, impersonal, } \\
\text { kadang agak melelahkan }\end{array}$ \\
\hline $\begin{array}{c}\text { Peaceful \& } \\
\text { Quiet }\end{array}$ & $\begin{array}{l}\text { Taman kota, taman daerah } \\
\text { perumahan, tempat untuk } \\
\text { rekreasi, pinggiran kota, daerah } \\
\text { natural, }\end{array}$ & Damai dan tenang, berumput \\
\hline Historic & $\begin{array}{l}\text { daerah lama di pusat kota, old } \\
\text { local downtown }\end{array}$ & $\begin{array}{l}\text { Bangunan bersejarah, aktivitas } \\
\text { dan layanan yang didirikan } \\
\text { sejak lama }\end{array}$ \\
\hline
\end{tabular}

Vibrant

Suasana vibrant mengacu pada pengalaman positif di jalanan-jalanan kota yang dinamis. Hal tersebut terutama banyaknya pejalan kaki di kalan di daerah dan fasilitas pusat kota yang padat. Penelitian yang dilakukan Stefansdottir (2018) mengungkapkan bahwa suasana ini mencakup unsur budaya dan gaya hidup di kawasan pusat kota, lingkungan lokal yang dekat pusat kota, yang ditandai kehidupan jalanan perkotaan yang dinamis dan terkadang multikultural urban streetlife dan outdoor markets. Seseorang dapat saja menginterpretasikan jalanan kota memiliki variasi, dengan ciri khas masing-masing toko unik dan terpisah, termasuk orang yang duduk di kafe pinggiran jalan. Orang yang cenderung senang dengan suasana vibrant umumnya senang dan menghargai ketika berjalan-jalan di area terbuka dan berjalan dari satu toko ke toko lainnya (Stefansdottir, 2018). 

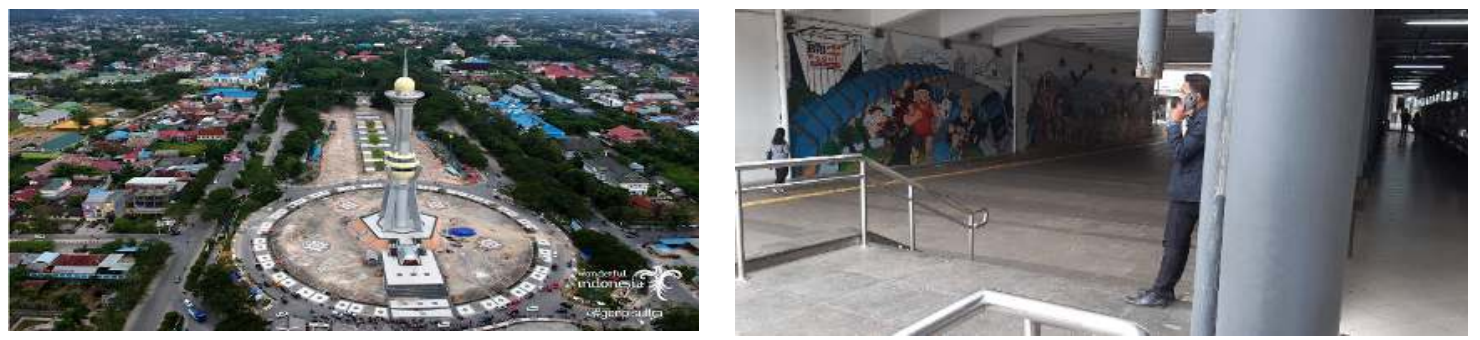

Gambar 4 dan 5. Contoh suasana vibrant. Jalanan kota di Tugu MTQ, Kendari (kiri) dan

Trotoar Stasiun Sudirman, Jakarta Selatan (kanan). Sumber: Genpisulta, 2020; Penulis, 2019

\section{Consumerism}

Suasana ini mengarah kepada pusat perbelanjaan (shopping malls). Riset yang dilakukan oleh Stefansdottir (2018) mengatakan bahwa beberapa partisipannya kurang begitu menyukai suasana ini karena suara yang ribut dan kadang agak melelahkan. Mereka terpaksa pergi ke lokasi tersebut karena alasan tertentu, salah satuya untuk mendapatkan apa yang mereka butuhkan ketika barang tersebut tidak dijual di tempat lain. Beberapa partisipan ada yang menyukainya karena mudah berkendara ke sana. Akses parkir yang baik di pusat perbelanjaan juga mengundang orang-orang ke sana.
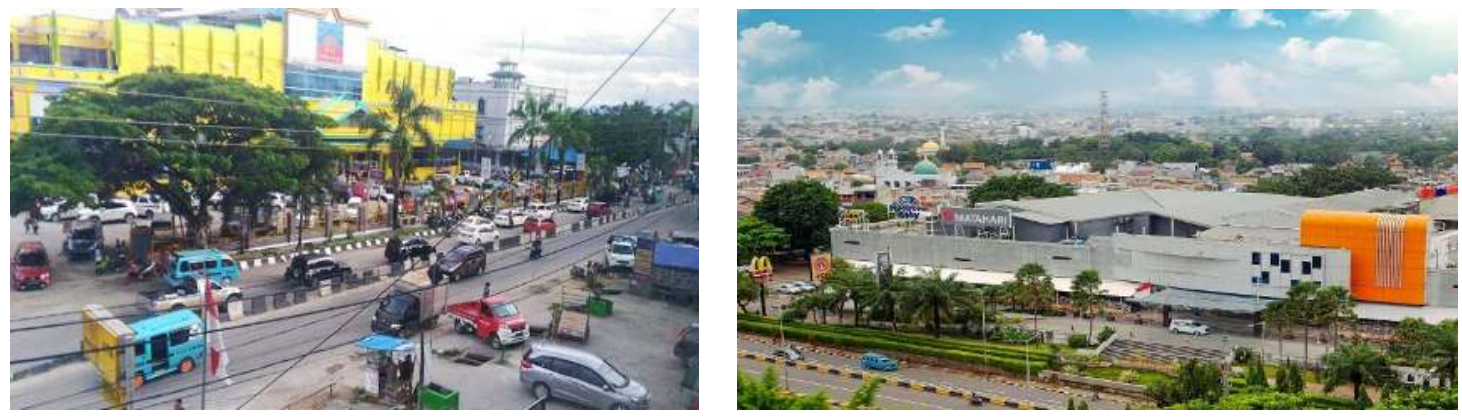

Gambar 6 dan 7. Contoh suasana consumerism. Mall Mandonga, Kendari (kiri) dan Plaza Kalibata, Jaksel (kanan). Sumber: Surahmin \& Ose, 2018; instagram plazajatinegara, 2020

\section{Peaceful and quiet}

Suasana peaceful and quiet mengacu pada tempat-tempat yang baik untuk rekreasi dan lingkungan hijau yang memiliki hubungan dengan alam. Stefasndottir (2018) dalam risetnya mengatakan semua partisipannya begitu menghargai lingkungan tersebut. Kawasan dalam perkotaan yang hijau juga ditemukan memiliki kualitas suasana atau atmosfer yang positif, seperti taman. Taman kecil dengan air mancur, bunga, dan pepohonan juga memberikan suasana damai dan tenang meskipun ukurannya kecil di kawasan pusat kota yang padat (Stefansdottir, 2018). 

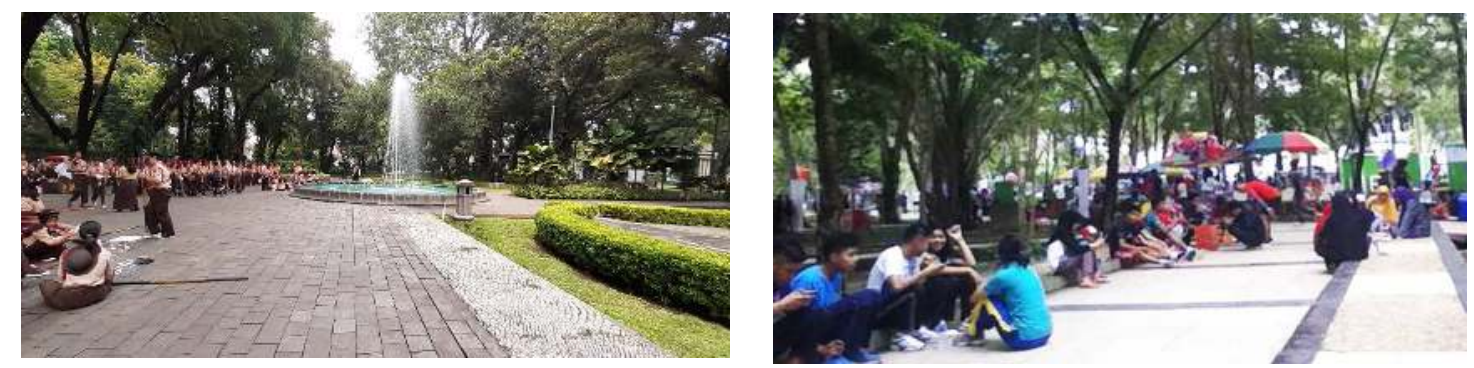

Gambar 8 dan 9. Contoh Suasana peaceful and quiet. Taman Suropati, jakarta Selatan (kiri) dan Taman Kota Kendari (kanan). Sumber: penulis, 2019; Budianto dan Jumriati, 2016

\section{Historic}

Suasana historic mengacu pada suasana yang diciptakan oleh bangunan-banguna bersejarah, termasuk sejarah-sejarah yang ada ruang publik, misalnya kantor pemerintah, tugu nasional, fasilitas lama, dan lainnya. Suasana historic paling sering menjadi bagian dari area pusat kota lama di kota ataupun bagian dari pusat-pusat lokal. Stefansdottir (2018) mengatakan partisipannya senang melihat rumah yang indah dan bangunan bersejarah ketika berjalan-jalan. Beliau mengatakan suasana historic merupakan bagian penting dari keseluruhan atmosfer positif. Seseorang dapat saja mengatakan suasana tersebut yang membuatnya berbeda dari tempat lain di wilayah metropolitan lainnya dan memiliki dampak yang besar untuk lingkungan (Stefansdottir, 2018).
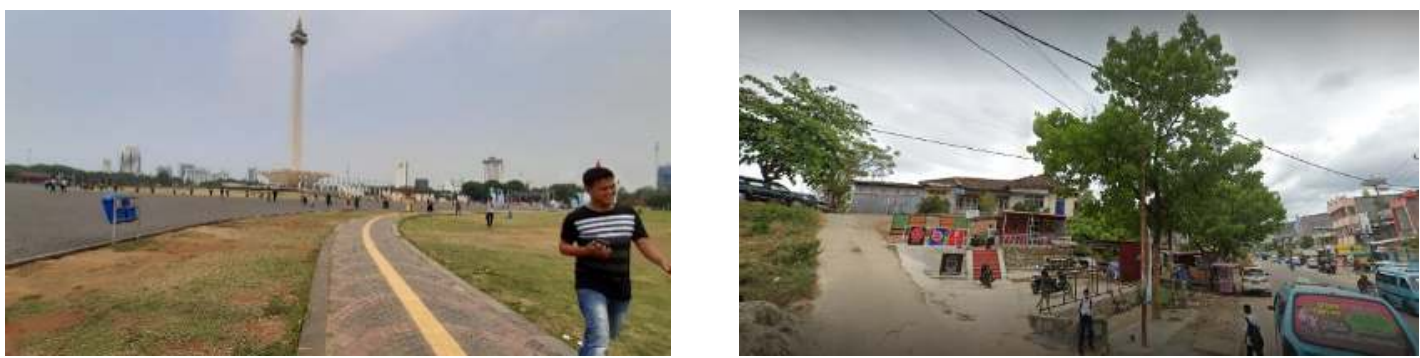

Gambar 10 dan 11. Contoh Suasana historic. Tuga Monas (kiri) dan Angkringan Kota Lama Kendari daerah Sidohoa (kanan). Sumber: Penulis, 2019; googlemap, 2019

Suasana lingkungan tertentu turut bertanggungjawab atas perasaan kita tentang lingkungan tersebut karena unsur lingkungan menimbulkan kesan pada perasaan seseorang tentangnya. Atmosfer, mungkin memiliki beberapa tipe baik dengan karakteristik positif mapupun negatif (Stefansdottir, 2018). Berbagai perasaan emosi positif dapat diekspresikan dengan senyum duchenne. Senyum jenis ini cenderung melaporkan berbagai pengalaman emosi-emosi positif sebagai respon terhadap stimuli visual, auditori, gustatori, maupun 
kinetik. Penelitian ini diharapkan dapat melihat bahwa pada suasana-suanana tertentu, senyum duchenne lebih sering terjadi dibandingkan suasana kota lainnya.

Peneliti memilih kota Kendari dan kota administrasi Jakarta Selatan sebagai tempat observasi. Hal tersebut karena kedua kota memiliki persamaan dan juga perbedaan. Persamaannya adalah (1) sama-sama memiliki fasilitas yang baik. (2) Kedua kota memiliki indeks kebahagiaan nasional yang hampir sama, DKI Jakarta 7,33 total point dan Sulawesi Tenggara 7,22 total point. DKI Jakarta berada di peringkat 17, dan Sulawesi Tenggara berada di peringkat 18 nasional (BPS, 2017). Adapun perbedaannya adalah, saat observasi, beberapa pusat kota di Kota Lama Kendari sedang tahap renovasi dan pembongkaran ulang, misalnya kantor walikota yang dekat dengan Taman MTQ, yang juga sedang tahap renovasi.

\section{Metode Penelitian}

Penelitian ini bertujuan untuk melihat seberapa banyak ekspresi wajah tersenyum duchenne yang ada pada pusat-pusat kota di kota Kendari dan Jakarta Selatan. Ada beberapa fasilitas publik di kota Kendari yang sedang tahap pembangunan ulang, misalnya kota tua dan sekitar tugu Religi Kota lama Kendari. Penelitian ini menggunakan metode naturalistic observation. Naturalistic observation berusaha untuk melihat tingkah laku individu yang terjadi secara alami tanpa ada keinginan untuk melakukan intervensi sebagai bagian dari penelitian (Thomas, 2018).

Observer dalam penelitian bertindak secara pasif melakukan assesmen atau pengumpulan data. Sample diambil dengan menggunakan time samping. yaitu pengambilan sample representatif dalam interval waktu tertentu secara random atau terstrukur. Observer mengambil waktu 12 menit atau seperlima (1/5) jam setiap lokasi dalam 8.00 AM - 12.00 AM untuk melihat seberapa sering tingkah laku yang diobservasi muncul. Teknik pengambilan data yang digunakan adalah tally count. Proses Tally count umumnya observer menulis kapan dan seberapa banyak perilaku yang diamati terjadi dengan angka (Mehl dkk, 2012).

Tingkah laku yang diobservasi adalah ekspresi senyum duchenne smile. Definisi operasional dari jenis senyuman duchenne adalah sesuai dengan alat ukur FACS oleh Ekman dkk (2002) dan berdasarkan riset-riset sebelumnya dengan Indikator: (a) aktiviasi otot zygomatic major atau disekitar bibir yang memperluas mulut menjadi senyuman atau AU12 dan (b) aktivitas wajah bagian atas orbicularis oculi (pipi atas) atau AU6 sehingga menimbulkan lipatan di ujung kedua mata, seperti gambar 1 dan 2 diatas. Berbeda dengan 
Senyuman non-Duchenne, yang umumnya tidak memiliki lipatan di ujung luar mata atau indikator AU6, namun tetap melebarkan senyum seperti indikator AU12.

Definisi operasional dari suasana kota adalah delapan (8) fasilitas di pusat kota yang akan dijadikan sebagai tempat observasi, sesuai dengan teori suasana kota oleh Stefansdottir (2018). Observasi dilakukan pada hari sabtu, 23 November 2019 dari secara random memilih waktu dari pagi pukul 8 hingga jam 12 siang. Ada dua observer pada penelitian ini, yang pertama penulis sendiri di empat (4) daerah di Jakarta Selatan. Observer kedua berada di empat (4) daerah kota lama Kendari. Tempat observer melakukan penelitian dapat dilihat sebagai berikut:

Tabel 2. Lokasi Observer

\begin{tabular}{|c|c|c|}
\hline Suasana Kota & Lokasi & Karakteristik sesuai teori \\
\hline \multirow[t]{2}{*}{ Vibrant } & $\begin{array}{l}\text {-Trotoar stasiun Sudirman } \\
\text { (Jaksel) }\end{array}$ & $\begin{array}{l}\text { streetlife, banyak pejalan } \\
\text { kaki dan individu berhenti }\end{array}$ \\
\hline & $\begin{array}{lll}\text {-Trotoar } & \text { Tugu } & \text { Religi } \\
\text { (Kendari) } & & \end{array}$ & $\begin{array}{l}\text { di public space, dekat } \\
\text { fasilitas publik. }\end{array}$ \\
\hline Consumerism & $\begin{array}{l}\text {-Plaza Kalibata (Jaksel), } \\
\text {-Mall Mandonga (Kendari) }\end{array}$ & $\begin{array}{l}\text { Monoton, noisy, frustating, } \\
\text { impersonal, kadang sedikit } \\
\text { melelahkan. }\end{array}$ \\
\hline Peaceful \& Quiet & $\begin{array}{l}\text {-Taman Suropati (Jaksel), } \\
\text {-Taman kota (Kendari) }\end{array}$ & Damai, tenang, berumput. \\
\hline Historic & $\begin{array}{l}\text {-Monas (Jakarta), } \\
\text {-Angkringan Kota Lama } \\
\text { daerah Sidohoa (Kendari) }\end{array}$ & $\begin{array}{l}\text { bangunan bersejarah, } \\
\text { aktivitas dan layanan yang } \\
\text { didirikan sejak lama. }\end{array}$ \\
\hline
\end{tabular}

\section{HASIL DAN PEMBAHASAN}

Setelah melakukan observasi di delapan tempat yang berbeda, berikut jumlah senyuman duchenne selama 12 menit atau seperlima (1/5) jam di tempat tersebut:

Tabel 3. Jumlah Senyum Ducenne dari tally count observer

\begin{tabular}{ccc}
\hline Suasana Kota & Jakarta Selatan & $\begin{array}{c}\text { Kota Lama Kendari } \\
\text { (Kec. Mandonga) }\end{array}$ \\
\hline Vibrant & $\begin{array}{c}\mathbf{2 0} \\
\text { (Trotoar Stasiun Sudirman) }\end{array}$ & $\begin{array}{c}\mathbf{6} \\
\text { (Trotoar Tugu MTQ) }\end{array}$ \\
Consumerism & $\mathbf{1 9}$ & $\mathbf{2 0}$ \\
Peaceful \& Quiet & (Plaza Kalibata) & (Mall Mandonga) \\
& $\mathbf{1 5}$ & $\mathbf{1 2}$ \\
(Taman Suropati) & (Taman Kota)
\end{tabular}


Jurnal Planologi Vol. 18 No. 1, April 2021

\begin{tabular}{ccc} 
Historic & $\begin{array}{c}\mathbf{2 2} \\
\text { (Monas) }\end{array}$ & $\begin{array}{c}\mathbf{4} \\
\text { (Angkringan kota lama) }\end{array}$ \\
\hline TOTAL & $\mathbf{7 6}$ & $\mathbf{4 2}$ \\
\hline
\end{tabular}

Sumber : Survey Primer, 2019

Stefansdottir (2018) mengemukakan jenis suasana kota tertentu dapat meningkatkan kesehatan, kesejahteraan dan menambah pengalaman positif seseorang ketika berinteraksi di lingkungan. Berdasarkan hasil oberservasi, dapat dilihat kedua kota memiliki jumlah senyuman duchenne yang cenderung sama banyak di (1) pusat perbelanjaan, dan (2) taman. Kedua tempat tersebut adalah jenis suasana consumerism dan peaceful and quiet.

Namun, pada suasana vibrant, jumlah senyum duchenne yang dihitung lebih banyak di trotoar Stasiun Sudirman (yaitu 20), dibandingkan trotoar Tugu MTQ (yaitu 6) selama 12 menit. Adapun Stasiun Sudirman sendiri baru-baru ini telah selesai mempercantik trotoar, flyover, serta trowongan atau underpass mereka (Jeprima, 2019).

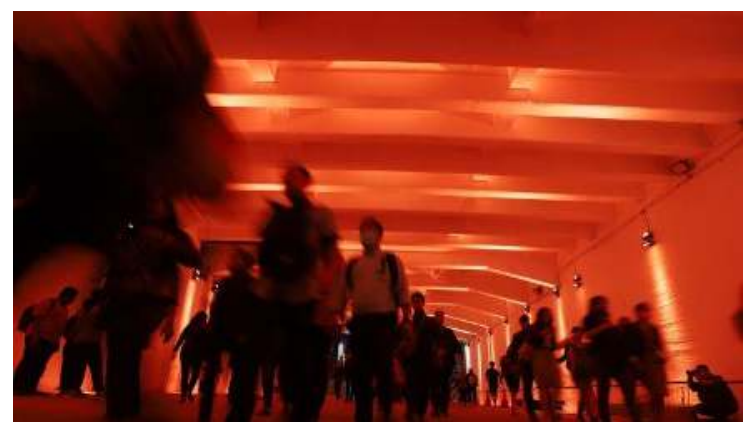

Gambar 12. Trowongan Statiun Sudirman. Sumber: Jeprima, 2019

Underpass stasiun Sudiman telah diberikan lampu-lampu penerangan berwarna merah, pink, dan kuning. Menurut Jeprima (2019), kebanyakan orang yang lewat terlihat berwajah ceria melintasi trowongan tersebut. Beberapa diantara mereka juga ada yang istirahat, singgah sejenak, dan kemudian berswafoto atau selfie.

Adapun Trotoar Tugu Persatuan MTQ Kendari, yang sempat berganti nama menjadi Tugu Religi di tahun 2016, berdasarkan berbagai sumber nampaknya renovasi yang dilakukan tahun 2016 masih berjalan pada waktu observasi (23 November 2019). Di tahun 2019, perbaikan yang dilakukan adalah bagian SSDC, pagar, dan pelataran. Lalu di tahun 2020, renovasi juga dilakukan untuk membenahi berbagai fasilitas, termasik keramik yang rusak (Heeryl, 2020). 


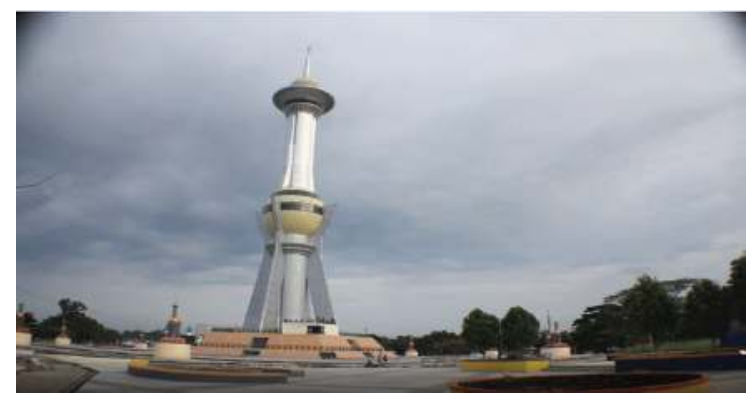

Gambar 13. Tugu Persatuan MTQ Kendari. Sumber: Heeryl, 2020

Berikut beberapa review tentang tugu Persatuan MTQ atau Tugu Religi ini menurut orang-orang yang pernah pergi ke sana yang tertulis di website googlemap pada tahun 2020:

"Tingkatkan perawatan taman taman. sehingga rumput liar tidak menjadi pemandangan yang merusak" - Priastuti (Desember 2020)

"Kebersihan terawat dengan baik, tinggal taman dan fasilitas publik perlu penerangan dan pengecetan kembali agar lebih menarik" - Santoso (Desember 2020)

"Cocok buat nongkrong bareng keluarga, teman, sahabat, pacar bahkan mantan pacar atau mau belanja pakaian serta nyobain jajanan yang ada" - Absor (September, 2020)

"Bagus sih tapi agak kotor tamannya" - Ilham (Desember 2020)

"Sebagai icon kota Kendari tentunya tempat ini menjadi tempat yang cukup menarik untuk dikunjungi, akan lebih baik jika dirawat kebersihanya. Saya menemukan tumpukan sampah dan cukup banyak ditiap sudut dan halaman utama. Untuk masuk ke tempat ini, anda tidak perlu membayar apapun alias gratis" Dwihana (Juni 2020)

Berdasarkan review diatas, dapat dikatakan Tugu Persatuan MTQ merupakan tempat yang menarik untuk dikunjungi secara bersama-sama sebagai icon kota. Namun, tingkat perawatan dan kebersihannya masih perlu ditingkatkan. Khususnya pada sudut-sudut taman dan halaman utama tugu.

Pada suasana historic, hasil observasi memperlihatkan ekspresi senyum duchenne lebih banyak di Tugu Monumen Nasional di pusat Jakarta (yaitu 22), dibandingkan angkringan kota lama Kendari Sodohoa (yaitu 6) selama 12 menit (1/5 jam). Namun, suasana historic yang ada di Tugu Monas mungkin berbeda dengan kondisi sekarang karena pemerintah kota DKI Jakarta telah merevitalisasi taman-taman Tugu Monas untuk tambahan fasilitas publik terkait formula E, serta berbagai fasilitas lainnya di awal tahun 2020 (Sofian dan Antonius, 2020). Hal tersebut dapat merubah persepsi seseorang terhadap berbagai tata ruang kota dan dapat mempengaruhi pengalaman emosi positif seseorang yang sebelumnya pernah ke sana, untuk sementara hingga rampung kembali. 
Berbagai fasilitas yang ada di daerah Sodohoa menurut observer, merupakan tempat bersejarah awal berdirinya kota lama Kendari yang dekat dengan pelabuhan di pesisir dan teluk Kendari. Pada tahun 2019, cukup banyak perubahan yang dilakukan oleh pemerintah maupun inisiatif-inisiatif masyarakat. Namun, hal tersebut membuat beberapa konflik antara pemkot dan warga mengenai manfaat beberapa lokasi di Sodohoa. Misalnya saja, pemerintah kota tidak mengetahui bahwa pelelangan ikan (TPI) di Sodohoa telah dijadikan pasar lokal. Sehingga, pemkot sendiri berusaha mengembalikan fungsi tempat tersebut kembali sebagai hanya pelelangan ikan (Rido, 2019). Kemudian, dua bulan sebelum observasi (Agustus 2019) juga terjadi pembongkaran puluhan lapak di sekitar angkringan kota lama khususnya lapak yang tidak menjual ikan (Heeryl, 2019). Observer berasumsi bahwa pemkot Kendari berusaha membuat daerah Sidohoa dekat angkringan lebih ke arah penjualan dan pelelangan ikan.

Stefansdottir (2018) mengemukakan suasana historic yang multifungsi atau mixed-use lebih dapat meningkatkan kesejahteraan individu. Sebaliknya, Suasana historic yang hanya memiliki satu fungsi, berdasarkan riset beliau cenderung membuat suasana kurang begitu 'terasa' atau lack of atmosphere (Stefansdottir, 2018). Adapun di kompleks Tugu Monas, ada beberapa jenis fasilitas lainnya yang terasa multifungsi. Diantaranya ada rumah makan atau restoran, mall, hotel, perkantoran pemerintah dan swasta, halte, stasiun commuterline, museum-museum nasional, menara untuk melihat pemandangan jauh dengan stetoskop, berbagai taman dengan fungsi berbeda. Ada yang untuk istirahat, untuk berolahraga, dan untuk melihat jenis-jenis tanaman hias.

Stefansdottir (2018) mengemukakan bahwa suasana jenis peaceful and quiet dan historic umumnya memiliki peran penting untuk meningkatkan kualitas hidup di perkotaan baik di pusat kota, maupun pusat-pusat lokal atau sub-urban. Suasana tersebut perlu juga di pinggiran kota yang berkembang karena, seseorang yang berada di suasana tersebut dapat berinteraksi sosial bersama-sama dan melakukan berbagai aktivitas yang cenderung positif dan sehat; misalnya saja sama-sama menikmati suasana lapangan hijau, rehat sejenak untuk rekreasi, berolahraga, mencoba berbagai masakan lokal di angkringan, termasuk singgah di kafe-kafe untuk bertemu satu sama lain dengan fasilitas publik yang baik.

Tabel 4. Senyum Duchenne yang terjadi bersama Interaksi Sosial di Lingkungan

\begin{tabular}{ccc}
\hline Suasana Kota & Jakarta Selatan & Kola Lama Kendari \\
\hline Vibrant & 16 dari 20 & 5 dari 6
\end{tabular}


Jurnal Planologi Vol. 18 No. 1, April 2021

\begin{tabular}{ccc}
\hline Suasana Kota & Jakarta Selatan & Kola Lama Kendari \\
\hline Consumerism & 18 dari 19 & 16 dari 20 \\
Peaceful \& Quiet & 13 dari 15 & 10 dari 12 \\
Historic & 19 dari 22 & 4 dari 4 \\
\hline TOTAL & $\mathbf{6 6}$ dari 76 & $\mathbf{3 5}$ dari 42 \\
\hline
\end{tabular}

Berdasarkan observasi tambahan, tingkah laku senyum duchenne di kedua kota umumnya terjadi ketika berinteraksi dengan orang lain di lingkungan. Effendi (2016) menjelaskan bahwa setiap orang memerlukan orang lain agar dapat meningkatkan kesejahteraannya yaitu dengan cara membangun relasi yang baik terhadap keluarga, teman, ataupun tetangga. Jaafar dkk (2014) dalam riset kualitatifnya menjelaskan bahwa $28,8 \%$ partisipannya yang berkebangsaan Indonesia melaporkan keluarga ataupun orang lain merupakan kontributor tertinggi sebagai sumber kebahagiaan mereka secara individual.

Riset tyang dilakukan oleh Chan (2020) menjelaskan bahwa budaya yang cenderung membuat seseorang lebih sering mengekspresikan diri lebih berkorelasi dengan nilai-nilai pro-environmental behavior atau tingkah laku menjaga alam dan nilai-nilai transcendence. Seseorang dapat mengekspresikan dirinya dapat dengan senyum duchenne maupun nonDuchenne. Berdasarkan berbagai riset sebelumnya, senyum duchenne disebut juga senyum yang betul-betul seseorang betul-betul merasakan emosi positif yang spontan. (Ekman dkk, 2002; Andrzejewski \& Mooney, 2016). Stefansdottir (2018) mengatakan bahwa suasana lingkungan turut bertanggungjawab atas perasaan kita tentang lingkungan tersebut karena unsur lingkungan menimbulkan kesan pada perasaan seseorang

\section{KESIMPULAN DAN SARAN}

Berdasarkan riset yang dilakukan di atas, dapat dilihat bahwa suanana kota yang dirawat dengan baik dan bersifat multifungsi (mixed-use) lebih sering terlihat senyum duchenne dibandingkan fasilitas kota yang belum rampung dalam aspek revitalisasi/renovasi dan kurang multifungsi. Namun, masih perlu penelitian lebih lanjut untuk melihat apakah suasana tertentu dapat mendukung ekspresi duchenne seseorang, dapat dengan tambahan metode lain (self-report, interview, teknik statistik tertentu, d1l), Observasi yang mengambil lebih banyak data juga dapat dilakukan misalnya pagi dan malam hari. Riset ini sendiri dilakukan hanya pada pagi hingga siang hari. 
Untuk meningkatkan suasana vibrant di kehidupan kota, pihak terkait dapat menambahkan fasilitas untuk mempercatik tempat untuk pejalan kaki seperti cahaya, baubauan, atau simuli lainnya. Perawatan fasilitas juga perlu dilakukan secara berkelanjutan. Tidak hanya membongkar secara besar-besaran fasilitas publik. Stefansdottir (2018) menjelaskan, atmosfer yang berkembang dalam waktu yang lama dan memiliki fungsi mixed-use, seperti suasana historic, kemungkinan individu akan mengalami suatu kesejahteraan yang lebih baik.

Penulis menyarankan fasilitas di pusat kota lama sekiranya dapat dibuat lebih multifungsi agar interaksi yang terjadi juga dapat beragam misalnya membangun tempat wisata, olahraga, event musik, museum atau pusat-pusat ramai lainnya. Stefansdottir (2018) menyarankan untuk mempromosikan karakteristik-karakteristik suasana peaceful \& quiet (ruang hijau), historic (gedung-gedung bersejarah yang dirawat baik), dan suasana yang lebih 'sosial' untuk diterapkan pada tingkat yang lebih besar dalam perencanaan pusat kota, dan pusat-pusat daerah tempat tinggal agar dapat meningkatkan lokasi-lokasi living areas dengan kualitas hidup yang baik bagi penghuninya.

\section{DAFTAR PUSTAKA}

Andrzejeski, A.S., \& Mooney, C.E. (2016). Service with a smile: Does the type of smile matter? Journal of Retailing and Consumer Services 29 (2016) 135-141

Badan Pusat Statistik (2017) Subdirektorat Statistik Ketahanan Wilayah: Indeks Kebahagiaan. CV Dharmaputra: Jakarta

Cameron, F.W.R., Brindley, P., Mears, M., McEwan, K., Ferguson, F., Sheffield, D., Jorgensen, A., Riley, J., Goodrick, J., Ballard, L., \& Richardson, M. (2020). Where the wild things are! Do urban green spaces with greater avian biodiversity promote more positive emotion on human? Urban ecosystems 23:301-317

Effendi, Nurlaila (2016). Konsep Flourishing dalam Psikologi Positif: Subjective Wellbeing atau berbeda? Universitas Katoliik Widya Mandala: Surabaya

Ekman, P., Friesen, W.V., Hager, J.C. (2002). The Facial Action Coding System, 2nd ed. Salt Lake City, UT: Re

Freeman, C., Dickinson, J.M.K., Porter, S., \& van Heezik, Y. (2012). My garden is an expression of me: Exploring householder's relationships with their gardens. Journal of Environmental Psychology 32(2012): 135-143

Gandy, M. (2017). Urban Atmospheres. Cultural geographies, vol 2017 24(3) 353-374

Gunnery, D.S. \& Hall, A.J. (2014). The duchenne smile and persuasion. Jurnal of Nonverbal behavior, 38, 181-194.

Hasse, J. (2014). Der Leib der Stadt. Studia Phaenomenologica 14 101-131 
Kytta, M.A. Broberg, M. Haybatollahi, K., \& Schmidt, T. (2016). Urban Happiness: Context- Sensitive Study of The Social Sustainability of Urban Settings. Environment and Planning B: Planning and Design 43 (1): 34-57.

Matsumoto, D. R., \& Juang, L. P. (2016). Culture and psychology $6^{\text {th }}$ edition. Belmont, CA: Wadsworth/Thomson

Mehl, M.R, Robbins, M.L., \& Deters, F.G. (2012). Naturalistic observation of healthrelevant social processes: the electronically activated recorder methodology in psychosomatics. Psychosom Med. 2012;74(4):410-7

Roberts, H., Sadler, J., \& Chapman, L. (2019). The values of twitter data for determining the emotional responses of people to urban green space: A case study and critical evaluation. Urban Studies vol 56 (4) 818-835

Stenffandottir, H (2018). The role of urban atmosphere for non-work activity locations, Journal of Urban Design, 23:3, 319-335

Svoray, T., Dorman, M., Shahar, G., \& Kloog, I. (2018). Demonstrating the effect of exposure to nature on happy facial expressions via Flickr data: Advantages of nonintrusive social network data analyses and geoinformatics methodologies. Journal of Environmental Psyhology, 58 (2018) 93-100

Thomas, P. (2018). Naturalistic Observation. Radford University: Department of Psychology

Yank, Y., Wu, X., Zhou, P., Gou, Y., \& Lu, Y. (2017). Towards a cycling-friendly city: An updated review of the associations between built environment and cycling behaviors (2007-2017). Journal of Transport \& Health, 14 (2019) 100613

Budianto, L. \& Jumriati. (2016). Selain berolahraga, ini alasan anak muda kendari ke taman kota. Diakses di www.zonasultra.co.id.https://zonasultra.com/selain-berolahragaini-alasan-lain-anak-muda-kendari-mengunjungi-taman-kota.html

Cooper, M (2018). Attractive smile youg lady photo. Diakses di pexels.com https://pexels.com/id-id/foto/atraktif-bagus-belum-tua-biasa-saja-1062280/

Genpisultra (2020). Jajanan kuliner di kawasan area MTQ Kendari. Diakses di www.genpisultra.my.id.https://www.genpisultra.my.id/2020/01/jajanan-kuliner-dikawasan-area-mtq.html

Googlemap (2020). Streetview KLBK Angkringan Kota Tua Kendari. Diakses di www.google.com/maps

Googlemap (2020). Reviews Tugu Persatuan MTQ Kendari. Diakses di www.google.com/maps

Googlemap (2020). Peta kota Kendari. Diakses di www.google.com/maps

Heeryl, 2020. Benahi kawasan Tugu Religi, pemprov Sutra Anggarkan 2 Milyar. Diakses di www.kendaripos.co.id.https://kendaripos.co.id/2020/02/benahi-kawasan-tugureligi-pemprov-sultra-anggarkan-rp-2-miliar/

Heeryl. (2019). Lapak liar di TPI Sodohoa dibongkar. Diakses di www.kendaripos.co.id. https://kendaripos.co.id/2019/08/lapak-liar-di-tpi-sodohoa-dibongkar/ 
Jurnal Planologi Vol. 18 No. 1, April 2021

Available: http://jurnal.unissula.ac.id/index.php/psa

Heryyl (2019) Jadikan Lokasi Wisata Terintegrasi, Gurbenur Poles Ulang Kawasan MTQ. Diakses di kendaripos.co.id.https://kendaripos.co.id/2019/02/jadikan-lokasi-wisataterintegrasi-gubernur-poles-ulang-kawasan-mtq/

Jeprima, W.D. (2019). Berita foto: Terowongan Cantik di Jakarta. Diakses di tribunnews.com, https:/www.tribunnews.com/metropolitan/2019/03/26/berita-fototerowongan-cantik-di-jakarta-spot-ciamik-untuk-selfie

Kurniawan (2016) Potret Tugu Religi, Landmark Kota Kendari yang Merana. Diakses di news.detik.co.id.https://news.detik.com/suara-pembaca/d-3207700/tugu-religilandmark-kota-kendari-yang-merana

Kalibatajkt (2020). Foto kalibata dari atas. Diakses di https://www.instagram.com/

Noesa, M (2015). Kota Lama Kendari Akan dibongkar. Diakses di www.kompasiana.com.https://www.kompasiana.com/mahajinoesa/54f36e83745513 982b6c75f0/kota-lama-kendari-akan-dibongkar

Rahayu, S (2019). Kantor Walikota Kendari Mulai Dibongkar. Diakses di www.zonasultra.com.https://zonasultra.com/gedung-kantor-wali-kota-kendarimulai-dibongkar-sulkarnain-berkantor-di-rujab.html

Rido. (2018). TPI Sodohoa dijadikan pasar. Kadis DKP mengaku kaget. Diakses di www.inilahsultra.com.https://inilahsultra.com/2019/07/15/tpi-sodohoa-dijadikanpasar-kadis-dkp-mengaku-kaget/

Surahmin, I. \& Ose, T. (2018). Sistem satu jalur di Mandonga tidak efektif. Diakses di www.zonasultra.co.id.https://zonasultra.com/sistem-satu-jalur-di-mall-mandongatidak-berjallan-efektif.html 